\title{
A comparison of conventional and grid techniques for chest radiography in field surveys
}

\author{
J. S. WASHINGTON, J. A. DICK, M. JACOBSEN ${ }^{1}$, and \\ W. M. PRENTICE ${ }^{2}$ \\ Medical Service, National Coal Board, and Institute of Occupational Medicine, Edinburgh ${ }^{1}$
}

\begin{abstract}
Washington, J. S., Dick, J. A., Jacobsen, M., and Prentice, W. M. (1973). British Journal of Industrial Medicine, 30, 365-374. A comparison of conventional and grid techniques for chest radiography in field surveys. The effect on the quality of chest radiographs using a reciprocating grid with a moderately high kilovoltage ( 96 to $105 \mathrm{kV}$ ) has been studied. A total of 1710 mineworkers had two postero-anterior chest radiographs taken at the same visit to a linked pair of mobile $x$-ray units. One film was taken with conventional exposure factors and the other with moderately high kilovoltage and a reciprocating grid. The grid was exchanged between the two units according to a randomized plan so that the first radiograph was not always taken with the same technique.

The $\mathbf{3} \mathbf{4 2 0}$ films so produced were subsequently assessed for quality by five doctors experienced in reading chest films. The films were examined singly in random order and the reader did not know which technique had been used for a given film.

Four of the readers recorded improved quality using the grid technique for films from men whose antero-posterior chest measurements exceeded $254 \mathrm{~mm}$ (10 in), but they preferred the conventional exposure technique for films from men whose chest measurements were less than $254 \mathrm{~mm}$. Results from all film pairs where a difference in quality was recorded showed no overall advantage for either technique.
\end{abstract}

The production of consistently high quality radiographs is an important requirement in any scheme for periodic radiological examinations of workers possibly exposed to an industrial chest hazard. In 1958 the National Coal Board (NCB) introduced a periodic $x$-ray scheme for mineworkers. The objectives of the scheme are twofold:

(a) to offer the safeguard of a periodic chest radiograph to coalminers; and

(b) to provide a continuing epidemiological picture of pneumoconiosis and thus measure the efficacy of the dust suppression techniques employed.

Mobile $x$-ray units using a large film (14 in $\times 14$ in:

${ }^{2}$ Now Director, Occupational Health Service, Eastern Regional Hospital Board, 4 Dunthorpe Terrace, Dundee
$35 \mathrm{~cm} \times 35 \mathrm{~cm})$ technique visit each colliery on a five-yearly basis and over $90 \%$ of miners come forward for examination. From the inception of the scheme radiographic technique and film quality have been monitored closely. Modifications to radiographic technique which might result in improved film quality have been investigated from time to time.

The generally accepted technique for chest radiography employs a kilovoltage of between 60 and 80 with an exposure time of 0.05 to 0.08 second. In recent years it has been suggested (Jacobson, Bohlig, and Kiviluoto, 1970) that, if a high kilovoltage $(110-140 \mathrm{kV})$ is used with a grid interposed between patient and film to reduce secondary radiation, the exposure times can be reduced by a factor of three. The resulting advantages claimed are: 
(a) the shorter exposure time lessens the risk of movement by the patient;

(b) secondary radiation is reduced with consequent improvement in film quality;

(c) the higher the kilovoltage employed, the smaller the effect of any drop in line voltage, poorly functioning timing equipment, and faulty selection of exposure factors; and

(d) the radiation dose to the patient is reduced (International Labour Office, 1970).

In 1969 the NCB mobile units were equipped with new $x$-ray apparatus. These units have facilities for the use of a reciprocating grid, a high speed rotating anode, and a moderately high kilovoltage. The maximum output which the units are adjusted to produce is $110 \mathrm{kV}$, and this is the minimum of Jacobson's 'high $\mathrm{kV}$ range'. If necessary, the $x$-ray sets can be modified to give $125 \mathrm{kV}$. However, such a modification would be at the expense of some loss in the lower kilovoltage range and this would be inconvenient given present NCB techniques.

Thus it was practicable to consider whether routine use of a reciprocating grid, with an adjustment to the kilovoltage range, might be a desirable general policy in the NCB's programme of chest radiography for coal miners. Although the limitations on kilovoltage range inherent in the available equipment precluded a systematic comparison with the technique as advocated by Jacobson et al. (1970), it was felt that any proposed major change in radiographic technique could be justified only if it resulted in substantial improvement in film quality.

At present about $10 \%$ of all films taken on NCB mobile units are regarded as showing some inadequacy of quality. It was considered that a substantial improvement should reduce the rate to $8 \%$ or lower.

It was recognized that if the specified improvement in quality was shown to be present then subsequent use of the grid technique for all Coal Board radiography might introduce a bias in the assessment of the amount of progression of pneumoconiosis occurring in groups of miners where two serial radiographs are available. Such assessments are made regularly for all British collieries and the results are expressed as a progression index for each colliery (Rogan, 1971). It was clear, therefore, that this problem might also have to be investigated. In the first place, however, a study was required of the question concerning the value of the grid technique in relation to film quality. The present report is concerned with a trial designed to answer this question.

\section{Methods}

Radiography

Three collieries, one in each of three separate coalfields, were selected for survey. The reasons for the study were explained to management and men through their colliery consultative committees. Two mobile $x$-ray vans were sent to each colliery and were linked in such a way that subjects could be $x$-rayed on two different machines without having to move outside. The $x$-ray generators were connected to the same power supply, and every endeavour was made to ensure that the supply was adequate to operate both units and was of low impedance. Naturally, the supplies varied to some extent at the three surveys. The output of each pair of sets was compared by taking step-wedge films, using the same factors, and comparing them densitometrically. Then the kilovoltage was adjusted to give as near as possible the same degree of blackening, e.g., $64 \mathrm{kV}$ on one unit was comparable with $60 \mathrm{kV}$ on another.

The number of kilovolt settings was limited to as few as possible, a maximum of three settings being used in the conventional kilovolt range, and three in the higher kilovolt range. The selection of kilovoltage in an individual case on a particular $x$-ray set was based on measurement of the postero-anterior (PA) diameter of the chest which graded each man into 'thin', 'medium', and 'thick'. Before each survey a number of men not taking part in the trial were $x$-rayed to establish techniques of both radiography and processing, and once established the latter was left unchanged throughout the trial.

Processing was carried out in a standard manner in an automatic processing unit, with fixed time and temperature and without distinction between grid and non-grid films, these being processed alternately. All films used for any one survey were by the same manufacturer and, when practicable, of the same batch number.

The 12 cassettes used in each survey were all of the same make and contained matched screens, six cassettes being used by each unit.

The exposure factors differed slightly in the three surveys but in general were as follows:

Grid technique $\quad 300 \mathrm{~mA}, 96-105 \mathrm{kV}, 6-18 \mathrm{~mA} / \mathrm{sec}$

$\quad(0.02-0.06 \mathrm{sec})$

Conventional $\quad 400 \mathrm{~mA}, 60-75 \mathrm{kV}, 24-48 \mathrm{~mA} / \mathrm{sec}$ technique (0.06-0.12 sec)

The exposure time was controlled throughout automatically by means of an Iontomat ${ }^{1}$. In the grid technique, the kilovoltage used was not high by present-day standards but was considerably more than sufficient to compensate for the presence of the grid.

The grid was changed from one unit to another according to a randomized plan in which in any six consecutive days both units had the use of the grid three times, and the maximum number of consecutive days using the grid was two. This procedure was designed to randomize possible effects associated with any particular combination of grid, generator, and radiographer and also to ensure that examinees who 'learned' to breathe more deeply on a second exposure were equally likely to meet either technique on that occasion. Films were photomarked in such a way that it could be deduced which unit had taken the film but not whether the film had been taken with or without the grid, except by reference to a list showing which unit had the use of the grid on a particular date.

${ }^{1}$ Made by Siemens A.G., Medical Engineering Group, Erlangen, West Germany 
Two record cards were prepared in advance for each man giving his identification data; such history as was required was written on one card by a clerk as the examinee entered the unit. The man then undressed to the waist, the antero-posterior (AP) chest diameter was measured and recorded on each card, and he was $x$-rayed by the first unit, one card being used for photomarking that film. He was then $x$-rayed by the second unit and the second card was used to photomark this second film.

A log of all films was kept on each unit. This was the key to identifying the technique adopted for each film; it also recorded the AP diameter of the chest and radiographic data.

Although circumstances dictated slight differences and deviations from the pre-arranged programme they did not affect the general plan substantially.

Examples of such deviations are:

Survey A The power supply fell below the desired standards and had some effect on film quality. A temporary breakdcwn of the high speed rotating anode made high kilovoltage technique impossible for a few days on one unit and thus caused a deviation from the randomized schedule.

Survey B Problems with the reciprocating grid mechanism on one of the units made exchange of the grid between the two units difficult, and a number of 'double exposed' grid films had to be withdrawn from the subsequent reading trials. These totalled 27 films.

Survey $\mathbf{C}$ The teams on this survey had benefited from the experience of the two previous ones, and in general the film quality and consistency were better and deviations from the pre-arranged plan were fewer.

\section{Film reading}

When the field surveys were complete, 1710 pairs of films were available for study. The number of examinees at surveys A, B, and C were 690,361 , and 659 respectively. All five doctors in charge of the $x$-ray centres in the coalfields took part in the assessment of film quality, including three of the authors (J.W., J.D., and W.P.). This was done at a central point over a two-day period.

The 3420 films were arranged in 10 lots, each lot being associated with one of 10 viewing boxes. Each lot consisted of four batches of films; three of these batches contained 100 films each, the fourth containing the balance of approximately 42. Individual films were arranged in random order within the batches, and each batch contained both the films from a pair. Each batch contained film pairs from the three surveys in proportion to the total number of examinees in each survey.

The film reading exercise was planned in 10 consecutive sessions. Each session consisted of the reading of one lot of films at one viewing box. On completing a session readers moved to another viewing box. Serial allocation of readers to viewing boxes was arranged using two independently randomized $5 \times 5$ Latin Squares. The effect of this was to ensure that after each reader had completed two sessions all 3420 films had been read once.

The quality criteria adopted for the first part of the exercise were purely radiographic (later termed criterion 1).
Each film was classified into one of the following categories:

UR unreadable

D dark

W white

F other interference (movement, positioning, etc.)

A acceptable

A+ above average.

Classification into one of the first four categories could be regarded as an indicator of poorer quality than was desirable. Classification as A or A + could be regarded as indicating a high quality film. At this stage the film readers were looking for any defect in film quality, no matter how small.

Because of the substantial film-reading load involved if all 1710 film pairs were to be assessed by all readers, arrangements were made for sequential analysis of results. The intention was to analyse sets of results as each reader completed a session. The sequential scheme was arranged so that a ratio of faulted films, grid:conventional, less than or equal to 0.8 would be detectable. This is equivalent to requiring a $20 \%$ improvement at least in the rate of faulted films. Stopping rules were defined so that the probability of deciding wrongly in favour of the grid technique $(\alpha)$ was less than or equal to $10 \%$; the probability of deciding wrongly that there was no difference between techniques $(\beta)$ was fixed at $2 \cdot 5 \%$.

By the time each reader had completed the first session, 856 film pairs had been read. Of these, 272 were pairs where only one of the films was scored as satisfactory. The conventional technique was favoured 149 times $(55 \%)$; the grid technique was preferred 123 times $(45 \%)$. These results were sufficient to justify stopping the trial according to the sequential stopping rules, since it had been demonstrated that the required overall advantage for the grid technique was not present. By definition, the probability that this decision was in error was less than or equal to $2.5 \%$. However, while the calculations described above were being made, further reading sessions had been completed. It was decided at this stage to continue the study for a limited period on the following day in order to obtain more information.

On the second trial day readers continued to code film quality as previously, but in addition were asked to consider also the question: 'Does the quality of the film interfere with your ability to diagnose pneumoconiosis?' (later termed criterion 2). If the reader's answer to this question was 'No' then the film was regarded as of acceptable quality; otherwise it was classified as of lower quality.

\section{Results}

At the end of the trial seven sessions had been completed. All readers read 7/10ths of all the films although the actual set of films seen by each reader differed, and by virtue of the trial design all films were read on three occasions by different readers and half of the films were read a fourth time by a fourth reader. The criterion of quality was recorded in all seven sessions; that of suitability for diagnostic purposes was also included in the last two.

The results are summarized in Table 1 . It is 
apparent from the lower section of Table 1 (All surveys) that overall the film readers showed no clear preference for either technique, and this was the conclusion drawn at an earlier stage from the sequential analysis. Yet it is apparent also that this general conclusion of 'no difference' is a consequence of opposite tendencies in films from survey $A$ on the one hand, where the grid technique was preferred, and films from surveys B and C, where the conventional technique was preferred.

The statistical significance of differences in results between and within the three surveys cannot be assessed by considering the data as presented in Table 1 because these tabulations describe repeated readings of the same film pairs by different readers; these judgements are not statistically independent. More detailed analyses follow.

Table 2 gives the pooled results from all three surveys for each of the five film readers. It will be seen from section iii in Table 2 that on the second trial day four of the readers decreased the rate at which they faulted films for quality (R) by criterion 1. In contrast, reader 3 more than doubled his earlier low rate, and these opposite tendencies result in very similar overall rates $(27 \%$ and $25 \%)$. Using criterion 2, all readers faulted a lower proportion of films to varying degrees. Overall, the percentage of films faulted was halved (from $25 \%$ to $12 \%$ ).

Information concerning a possible difference be- tween the two radiographic techniques is provided by those pairs where one film had a different quality assessment from the other (section iv of Table 2). Again, the overall rates at which such pairs were identified using criterion 1 were very similar on the two days-1 $142 / 4280=27 \%$ on the first day and $450 / 1710=26 \%$ on the second day. Differences between readers follow a similar pattern to that apparent from the overall percentage of faulted films (R), but it must be remembered that no two readers read exactly the same set of films.

Section $\mathrm{v}$ of Table 2 shows the variation between readers in their assessments of the relative merits of the two radiological techniques. The formal statistical test to compare the techniques (McNemar test) is based on whether the percentages shown (P) differ significantly from $50 \%$. Only six of the 15 percentages recorded there favour the grid technique when results from all three surveys are pooled. The most favourable single result for the grid technique was from reader 2 , who in 40 out of 68 pairs $(59 \%)$ read the grid film as acceptable and faulted the conventional film using criterion 1 on the second day. Even this single result, taken in isolation, would be expected to arise by chance about nine times in one hundred if there is really no difference between the two techniques in terms of the defined quality criterion.

The pooled results from the three surveys are

TABLE 1

Distribution of Film Pairs (All Readings)

\begin{tabular}{|c|c|c|c|c|c|c|c|c|}
\hline \multirow{2}{*}{\multicolumn{3}{|c|}{ Grid technique }} & \multicolumn{3}{|c|}{$\begin{array}{l}\text { Criterion 1: } \\
\text { Film quality }\end{array}$} & \multicolumn{3}{|c|}{$\begin{array}{c}\text { Criterion 2: } \\
\text { Diagnostic suitability }\end{array}$} \\
\hline & & & Accepted & Faulted & Total & Accepted & Faulted & Total \\
\hline Survey A & $\begin{array}{l}\text { Accepted } \\
\text { Faulted }\end{array}$ & $\begin{array}{l}. . \\
\cdots\end{array}$ & $\begin{array}{r}1512 \\
236\end{array}$ & $\begin{array}{l}441 \\
228\end{array}$ & $\begin{array}{r}1953 \\
464\end{array}$ & $\begin{array}{r}590 \\
26\end{array}$ & $\begin{array}{l}46 \\
28\end{array}$ & $\begin{array}{r}636 \\
54\end{array}$ \\
\hline Total .. & . & . & 1748 & 669 & 2417 & 616 & 74 & 690 \\
\hline Survey B & $\begin{array}{l}\text { Accepted } \\
\text { Faulted }\end{array}$ & $\begin{array}{l}. \\
\cdots\end{array}$ & $\begin{array}{l}420 \\
286\end{array}$ & $\begin{array}{l}167 \\
390\end{array}$ & $\begin{array}{l}587 \\
676\end{array}$ & $\begin{array}{r}219 \\
61\end{array}$ & $\begin{array}{l}39 \\
42\end{array}$ & $\begin{array}{l}258 \\
103\end{array}$ \\
\hline Total .. & . & $\cdots$ & 706 & 557 & 1263 & 280 & 81 & 361 \\
\hline Survey C & $\begin{array}{l}\text { Accepted } \\
\text { Faulted }\end{array}$ & $\begin{array}{l}\cdots \\
\cdots\end{array}$ & $\begin{array}{r}1665 \\
293\end{array}$ & $\begin{array}{l}169 \\
183\end{array}$ & $\begin{array}{r}1834 \\
476\end{array}$ & $\begin{array}{r}570 \\
42\end{array}$ & $\begin{array}{l}28 \\
19\end{array}$ & $\begin{array}{r}598 \\
61\end{array}$ \\
\hline Total .. & $\cdots$ & . & 1958 & 352 & 2310 & 612 & 47 & 659 \\
\hline All Surveys & $\begin{array}{l}\text { Accepted } \\
\text { Faulted }\end{array}$ & $\begin{array}{l}\cdots \\
\cdots\end{array}$ & $\begin{array}{r}3597 \\
815\end{array}$ & $\begin{array}{l}777 \\
801\end{array}$ & $\begin{array}{l}4374 \\
1616\end{array}$ & $\begin{array}{r}1379 \\
129\end{array}$ & $\begin{array}{r}113 \\
89\end{array}$ & $\begin{array}{r}1492 \\
218\end{array}$ \\
\hline Total . . & . & . & 4412 & 1578 & $5990^{1}$ & 1508 & 202 & 1710 \\
\hline
\end{tabular}

${ }^{1}$ On the second day both criterion 1 and criterion 2 were recorded for each film and the 'criterion 1 readings' from the second day are included in the figures. 
TABLE 2

RESULTS FOR EACH READER

\begin{tabular}{|c|c|c|c|c|c|c|c|c|c|c|c|c|}
\hline \multicolumn{2}{|l|}{ i } & \multicolumn{2}{|c|}{ ii } & \multicolumn{3}{|c|}{ iii } & \multicolumn{3}{|c|}{ iv } & \multicolumn{3}{|c|}{$\mathbf{v}$} \\
\hline & & \multicolumn{2}{|c|}{$\begin{array}{l}\text { No. of film } \\
\text { pairs read }\end{array}$} & \multicolumn{3}{|c|}{$\begin{array}{c}\text { No. of faulted } \\
\text { films as a } \\
\text { percentage of all } \\
\text { films read }\end{array}$} & \multicolumn{3}{|c|}{$\begin{array}{l}\text { No. of pairs } \\
\text { where only one } \\
\text { of the pair } \\
\text { was acceptable }\end{array}$} & \multicolumn{3}{|c|}{$\begin{array}{c}\text { No. of pairs } \\
\text { where grid film } \\
\text { was acceptable and } \\
\text { conventional film } \\
\text { was faulted, } \\
\text { as a percentage } \\
\text { of } n \\
P(\%)\end{array}$} \\
\hline $\begin{array}{ll}\text { Day } & . \\
\text { Criterion } & \ldots\end{array}$ & $\ldots$ & $\begin{array}{l}1 \\
1\end{array}$ & $\begin{array}{c}2 \\
1 \text { and } 2\end{array}$ & $\begin{array}{l}1 \\
1\end{array}$ & $\begin{array}{l}2 \\
1\end{array}$ & $\begin{array}{l}2 \\
2\end{array}$ & $\begin{array}{l}1 \\
1\end{array}$ & $\begin{array}{l}2 \\
1\end{array}$ & $\begin{array}{l}2 \\
2\end{array}$ & $\begin{array}{l}1 \\
1\end{array}$ & $\begin{array}{l}2 \\
1\end{array}$ & $\begin{array}{l}2 \\
2\end{array}$ \\
\hline $\begin{array}{r}\text { Reader } \begin{array}{r}1 \\
2 \\
3\end{array} \\
4 \ldots \\
4 \ldots \\
5 \ldots \\
\text { All readers }\end{array}$ & $\begin{array}{l}\ldots \\
\cdots \\
\cdots \\
\cdots \\
\cdots\end{array}$ & $\begin{array}{r}858 \\
857 \\
855 \\
855 \\
855 \\
4280\end{array}$ & $\begin{array}{r}337 \\
344 \\
343 \\
343 \\
343 \\
1710\end{array}$ & $\begin{array}{l}18 \\
23 \\
12 \\
46 \\
36 \\
27\end{array}$ & $\begin{array}{l}16 \\
16 \\
26 \\
30 \\
38 \\
25\end{array}$ & $\begin{array}{r}5 \\
11 \\
7 \\
16 \\
22 \\
12\end{array}$ & $\begin{aligned} & 198 \\
& 216 \\
& 145 \\
& \\
& 319 \\
& 264 \\
& 1142\end{aligned}$ & $\begin{array}{r}63 \\
68 \\
105 \\
108 \\
106 \\
450\end{array}$ & $\begin{array}{r}27 \\
48 \\
29 \\
71 \\
67 \\
242\end{array}$ & $\begin{array}{l}33 \\
49 \\
50 \\
50 \\
54 \\
47\end{array}$ & $\begin{array}{l}35 \\
59 \\
50 \\
53 \\
54 \\
51\end{array}$ & $\begin{array}{l}40 \\
56 \\
24 \\
58 \\
40 \\
47\end{array}$ \\
\hline
\end{tabular}

TABLE 3

Distribution of Film Pairs where Difference in Quality Assessment was recorded (n) using Criterion 1, by Preferred TechniQue and Chest Thickness

\begin{tabular}{|c|c|c|c|c|c|}
\hline & & $<254$ & $\geqslant 254$ & Total & \\
\hline $\begin{array}{l}\text { Grid better } \\
\text { Conventional better }\end{array}$ & $\begin{array}{l}\cdots \\
\cdots\end{array}$ & $\begin{array}{l}33 \\
75\end{array}$ & $\begin{array}{l}55 \\
98\end{array}$ & $\begin{array}{r}88 \\
173\end{array}$ & Reader 1 \\
\hline Total .. & . & 108 & 153 & 261 & $x_{\mathrm{c}}^{2}=0.6$ \\
\hline $\begin{array}{l}\text { Grid better } \\
\text { Conventional better }\end{array}$ & $\begin{array}{l}\cdots \\
\cdots\end{array}$ & $\begin{array}{l}47 \\
78\end{array}$ & $\begin{array}{l}98 \\
61\end{array}$ & $\begin{array}{l}145 \\
139\end{array}$ & Reader 2 \\
\hline Total .. $\quad \ldots$ & $\ldots$ & 125 & 159 & 284 & $x_{c}^{2}=15 \cdot 2$ \\
\hline $\begin{array}{l}\text { Grid better } \ldots \\
\text { Conventional better } .\end{array}$ & $\begin{array}{l}\cdots \\
\cdots\end{array}$ & $\begin{array}{l}23 \\
62\end{array}$ & $\begin{array}{r}102 \\
63\end{array}$ & $\begin{array}{l}125 \\
125\end{array}$ & Reader 3 \\
\hline Total .. & $\cdots$ & 85 & 165 & 250 & $x_{c}^{2}=25.7$ \\
\hline $\begin{array}{l}\text { Grid better } \\
\text { Conventional better }\end{array}$ & $\begin{array}{l}\cdots \\
\cdots\end{array}$ & $\begin{array}{r}79 \\
126\end{array}$ & $\begin{array}{r}138 \\
84\end{array}$ & $\begin{array}{l}217 \\
210\end{array}$ & Reader 4 \\
\hline Total .. & .. & 205 & 222 & 427 & $x_{c}^{2}=22.9$ \\
\hline $\begin{array}{l}\text { Grid better } \\
\text { Conventional better }\end{array}$ & $\begin{array}{l}\ldots \\
\cdots\end{array}$ & $\begin{array}{l}77 \\
98\end{array}$ & $\begin{array}{r}127 \\
68\end{array}$ & $\begin{array}{l}204 \\
166\end{array}$ & Reader 5 \\
\hline Total ... & . & 175 & 195 & 370 & $x_{c}^{2}=15.8$ \\
\hline
\end{tabular}



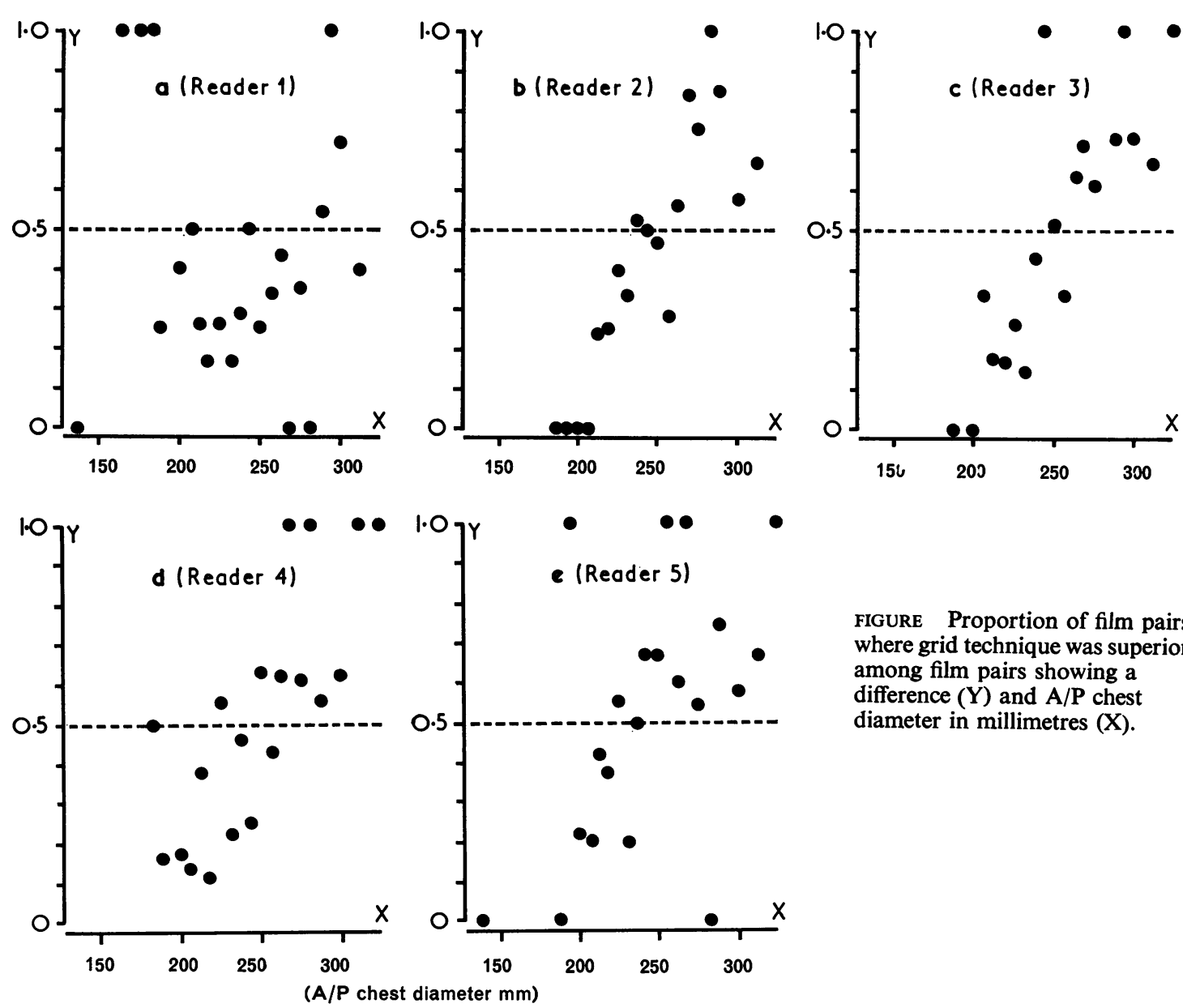

FIGURE Proportion of film pairs where grid technique was superior among film pairs showing a difference $(Y)$ and $A / P$ chest diameter in millimetres $(\mathrm{X})$.

considered further in Figures 1a to e. They show each reader's preferences, by criterion 1 , in relation to the distribution of chest measurements of men whose film pairs contributed to the comparison between techniques ( $\mathrm{n}$ in Table 2). Four of the five readers evidently favoured the grid technique more frequently when the subjects had thicker chests. The statistical significance of the linear trend in Figures $1 \mathrm{~b}, \mathrm{c}, \mathrm{d}$, and e was verified approximately by consideration of the correlation coefficient between chest measurements and a suitable mathematical transformation (the angular transformation) of the proportions of film pairs favouring the grid technique. The correlation coefficients were $0.83,0.79$, 0.76 , and 0.48 for readers $2,3,4$, and 5 respectively. Even the result for reader 5 (with 19 degrees of freedom) is statistically significant at the $5 \%$ level when tested formally; but it will be noted that the degrees of freedom available are determined by the number of ranges of chest diameters into which men were grouped. These groupings were made in a convenient but none the less arbitrary manncr. 'This caveat concerning the results from reader 5 refers only to the test of linear trend: there is no ambiguity about the conclusion that readers $2,3,4$, and 5 favoured the grid techniques when used for men with thicker chests. This can be seen in Table 3; the values of the $\chi^{2}$ statistics for readers 2 to 5 are highly significant $(P<0.001)$. The complementary inference should be noted: points above and below the dotted lines in Figures 1b to e are distributed evenly, confirming that in the judgement of readers 2 to 5 the preference for the grid technique among the thicker chested men was offset approximately by the better performance of the conventional technique among men with lower chest measurements. Reader 1 (Fig. 1a) tended to prefer the conventional technique irrespective of chest diameter.

The observation that readers' assessments of technique were dependent to some degree on the chest diameters of the men surveyed suggests that this factor may have contributed to the differences 
TABLE 4

Anteroposterior Chest Measurements (mm) of Examinees

\begin{tabular}{|c|c|c|c|c|c|c|c|c|c|c|}
\hline & & & & & & & \multicolumn{4}{|c|}{ Survey } \\
\hline & & & & & & & $A$ & $\boldsymbol{B}$ & $C$ & All \\
\hline $\begin{array}{l}\text { Number of men } \\
\text { Mean chest thickness (mm) } \\
\text { Standard deviation } \quad .\end{array}$ & $\begin{array}{l}\cdots \\
\cdots \\
\cdots\end{array}$ & $\begin{array}{l}\cdots \\
\cdots \\
\cdots\end{array}$ & $\begin{array}{l}\cdots \\
\cdots \\
\cdots\end{array}$ & $\begin{array}{l}\cdots \\
\cdots \\
\cdots\end{array}$ & $\begin{array}{l}\cdots \\
\cdots \\
\cdots\end{array}$ & $\begin{array}{l}\cdots \\
\cdots \\
\cdots\end{array}$ & $\begin{array}{r}6891 \\
264 \cdot 2 \\
0 \cdot 9\end{array}$ & $\begin{array}{r}361 \\
243 \cdot 8 \\
1 \cdot 2\end{array}$ & $\begin{array}{r}659 \\
231 \cdot 1 \\
0.9\end{array}$ & $\begin{array}{r}1709^{1} \\
246 \cdot 4 \\
1 \cdot 1\end{array}$ \\
\hline \multicolumn{4}{|c|}{ Percentage with chest thickness $\geqslant 254 \mathrm{~mm}$. . } & $\ldots$ & . & . & 76 & 45 & 22 & 48 \\
\hline
\end{tabular}

${ }^{1}$ Chest thickness was not recorded for one man in survey $\mathbf{A}$.

in results between surveys apparent from Table 1. Table 4 shows differences in mean chest diameters consistent with the results in Table 1 , and this matter is examined further in Table 5.

Column 1 of Table 5 shows the distribution of film pairs, by reader and by survey, where only one of the pair was judged satisfactory according to criterion 1. The observed number of preferences for the grid technique (column 2) demonstrates the pattern expected from the results discussed above: readers 2 to 5 all favoured the grid technique in films from survey $\mathrm{A}$ where men had thicker chests on average. Reader 1 found little difference between techniques in survey A but he showed a marked preference for the conventional technique in films from survey $B$, and to a lesser extent in those from survey $\mathbf{C}$.

The detailed distribution of preferences, by reader,

TABLE 5

Number of Film Pairs where Grid Technique was preferred by Criterion 1, AND NuMBer EXPECTED IF DifFerenCES BETWEen SURVEYS ARE DUE ONLY TO DifFERENCES in Chest Thicknesses AMONG THE Men CONCERned

\begin{tabular}{|c|c|c|c|c|c|c|c|}
\hline Reader & Survey & $\begin{array}{l}n \\
(1)\end{array}$ & $\begin{array}{r}\text { No } \\
\text { pre } \\
\text { Observed } \\
\text { (2) }\end{array}$ & $\begin{array}{l}\text { id } \\
\text { Expected } \\
\text { (3) }\end{array}$ & $\begin{array}{l}x^{2}{ }_{1} \\
(4)\end{array}$ & $\begin{array}{l}x^{2} 3 \\
(5)\end{array}$ & $\begin{array}{c}P \\
(6)\end{array}$ \\
\hline 1 & $\begin{array}{l}\mathbf{A} \\
\mathbf{B} \\
\mathbf{C}\end{array}$ & $\begin{array}{r}90 \\
105 \\
66\end{array}$ & $\begin{array}{l}47 \\
17 \\
24\end{array}$ & $\begin{array}{l}31 \cdot 8 \\
34 \cdot 7 \\
21 \cdot 5\end{array}$ & $\begin{array}{r}10 \cdot 01 \\
12 \cdot 74 \\
2 \cdot 20\end{array}$ & 24.95 & $<0.001$ \\
\hline 2 & $\begin{array}{l}\mathbf{A} \\
\mathbf{B} \\
\mathbf{C}\end{array}$ & $\begin{array}{r}106 \\
88 \\
90\end{array}$ & $\begin{array}{l}68 \\
42 \\
35\end{array}$ & $\begin{array}{l}61 \cdot 7 \\
42 \cdot 0 \\
41 \cdot 3\end{array}$ & $\begin{array}{l}4.33 \\
0.02 \\
1.63\end{array}$ & 5.98 & $>0.1$ \\
\hline 3 & $\begin{array}{l}\mathbf{A} \\
\mathbf{B} \\
\mathbf{C}\end{array}$ & $\begin{array}{r}109 \\
94 \\
47\end{array}$ & $\begin{array}{l}79 \\
34 \\
12\end{array}$ & $\begin{array}{l}64 \cdot 2 \\
40 \cdot 7 \\
20 \cdot 0\end{array}$ & $\begin{array}{r}13 \cdot 27 \\
2 \cdot 23 \\
5 \cdot 30\end{array}$ & $20 \cdot 81$ & $<0.001$ \\
\hline 4 & $\begin{array}{l}\mathbf{A} \\
\mathbf{B} \\
\mathbf{C}\end{array}$ & $\begin{array}{r}216 \\
78 \\
133\end{array}$ & $\begin{array}{r}152 \\
34 \\
31\end{array}$ & $\begin{array}{l}121 \cdot 0 \\
35 \cdot 5 \\
60 \cdot 5\end{array}$ & $\begin{array}{r}30 \cdot 22 \\
0 \cdot 12 \\
26 \cdot 10\end{array}$ & $56 \cdot 44$ & $<0.001$ \\
\hline 5 & $\begin{array}{l}\mathbf{A} \\
\mathbf{B} \\
\mathbf{C}\end{array}$ & $\begin{array}{r}156 \\
88 \\
126\end{array}$ & $\begin{array}{l}95 \\
41 \\
68\end{array}$ & $\begin{array}{l}95.9 \\
45 \cdot 0 \\
63.0\end{array}$ & $\begin{array}{l}0.61 \\
0.64 \\
1 \cdot 10\end{array}$ & 2.43 & $>0.1$ \\
\hline
\end{tabular}

$\mathrm{n}=$ number of film pairs where only one of the pair was acceptable

$\mathbf{P}=$ probability of chance occurrence of $x_{3}^{3}$ under hypothesis that differences in preferences for grid technique between surveys are due only to differences in proportions of film pairs from men with chest diameters less than $254 \mathrm{~mm}$; see Appendix. 
survey, and chest diameter, is given in an Appendix. The results shown there were used to calculate the expected number of preferences for the grid technique if differences between surveys are explicable solely in terms of differences in the relative proportions of thicker chested men. These expectations are shown in column 3 of Table 5. Columns 4 and 5 of the Table show test statistics calculated from the data. In this context statistical significance of the $\chi^{2}{ }_{3}$ for each reader (column 5) refers to evidence against the hypothesis that variations in results between surveys are due only to variations in chest diameter. The highly significant value of $\chi^{2}{ }_{3}$ for reader 1 in Table 5 is not unexpected since it is evident from the results in Table 3 and Fig. 1a that his preference for the conventional technique was unrelated to chest diameter. Differences between surveys as judged by readers 2 and 5 are explicable in terms of differences in chest thickness. The results from readers 3 and 4 , however, demonstrate preferences for the grid technique in survey $\mathbf{A}$ and for the conventional technique in survey $\mathrm{C}$ which are not attributable wholly to the variation in chest measurements.

\section{Discussion}

It is recognized that the $x$-ray generators used in this study did not have a range of control settings wide enough to permit both conventional and high kilovoltage exposures of the levels now recommended in Scandinavia and the U.S.A. It cannot be assumed that films taken using a range of 96 to $105 \mathrm{kV}$ are of the same type as those produced using 125 to $140 \mathrm{kV}$. However, the trial design permits a realistic comparison of film quality from two radiographs of the same examinee by the two techniques as defined, and this was the object of the study reported now. No record has been found of a similar controlled trial.

The trial was designed as a preliminary assessment of a modification in radiographic technique. It was hoped that it might demonstrate advantages justifying its introduction for all routine radiography in the National Coal Board. Sequential analysis was adopted so that if a clear-cut decision in favour of the grid technique had been possible at an early stage then the trial would have been stopped; further studies would have been planned to investigate the likely effect of the change in technique on the assessments of serial films for radiological progression of pneumoconiosis. In the event no such decision was justified by the sequential analysis; but the subsequent more detailed study of results reported now has revealed a number of interesting methodological lessons useful in planning trials of radiographic technique.

Although Table 2 shows that the two criteria of film quality used gave similar overall assessments of the relative merits of the two techniques, it is clear that judgement as to whether a film is of 'acceptable' quality or not is critically dependent on how the criterion is defined. When considering suitability of films for diagnostic purposes (criterion 2) the overall rate at which films were judged to be below optimum quality $(12 \%)$ was similar to that normally experienced in the NCB's Periodic $X$-ray Scheme. The more general criterion 1 doubled the rate of faulted films. This experience emphasizes the necessity for careful definition of quality criteria in studies of this kind. The design of the present trial, and the fact that it was not possible for readers to identify which exposure technique had been used for any particular film, should have ensured that the hypercritical approach using criterion 1 will affect results from both series of films to a similar extent.

The results show differences between readers in their interpretation of quality criteria, in diurnal variation using the same criterion (section iii of Table 2), and in their preferences for films made at different surveys (Table 5). Of particular interest is the more detailed analysis of results from reader 1 in Table 5. His overall preference for the conventional technique is seen to be due primarily to his reactions to films from survey B, where, out of 105 film pairs containing one faulted and one acceptable film, 88 of the preferences were for the conventional technique and only 17 for the grid technique. Reader 1 is the medical officer in charge of NCB radiological services in the area where survey B was conducted. Films from all three surveys were present in representative proportions in the batches prepared for the film reading; their order within batches was randomized and reader 1 was not consciously able to identify films prepared by his own $x$-ray unit. Yet the conspicuous maverick result in Table 5 suggests that subconsciously he recognized some aspect of technique in these films and that this may have affected his decision as to which films were acceptable. This is a reminder that however carefully a trial is designed, assessment of radiographs involves subjective factors. When data are required for epidemiological purposes it is demonstrably prudent to arrange for assessment of films by more than one reader.

Figure 1 and Table 3 show a relationship between advantages associated with modifications in radiographic technique and anthropometric measurements of the subjects which merits more precise quantification in further studies. The findings demonstrate also the inherent danger of using global judgements and sequential methods of analysis, even when such an approach appears to be justified. It was fortuitous that variations in chest diameters between surveys were more or less evenly balanced (Table 4). Such differences in physical characteristics are well known (McLintock, 1971), with a trend 
from north to south of Britain towards taller and heavier builds. The miners in this investigation followed this pattern; the differences observed might have been anticipated, but they were not. If only one survey had been conducted, say survey A or survey $\mathrm{C}$, then the results from the sequential analysis might have been very different and quite misleading.

There are so many variables involved in diagnostic radiography, particularly in field surveys, that it is well-nigh impossible to plan a fully controlled trial on one single aspect of radiography. Nevertheless, it is considered that this investigation was as carefully controlled as circumstances permitted and that the main conclusion, as it affects the National Coal Board's radiological services, is valid. This is that in general, for full size chest radiographs in field surveys, there is little to choose between the quality of films produced by conventional techniques and those taken using a grid and moderately high kilovoltage, always assuming that all reasonable care is taken over the other factors involved. However, it appears that for examinees with thicker chests (over $254 \mathrm{~mm}$ ) there are advantages associated with the use of the grid technique as described. Conversely, there is evidence that for individuals with smaller chest diameters, film quality is better using conventional methods.

In spite of the definite advantages resulting from the use of a grid in thick chested individuals, its use has not as yet been adopted by the National
Coal Board owing to the practical difficulties of inserting the grid and adjusting the exposure factors during a busy survey, and the possible effect on progression reading.

The two other film readers were our colleagues Dr. J. G. Bennett and Dr. D. J. Thomas.

Dr. J. M. Rogan suggested that this study should be made. We are grateful to him and to Dr. J. S. McLintock for encouragement and assistance throughout. The authors wish to thank their many colleagues in the NCB's Radiological Service who contributed-radiographers, technicians, and clerks. The willing collaboration of the miners was, of course, essential; we are very grateful to them.

\section{References}

International Labour Office (1970). Radiological technique. In International Classification of Radiographs of Pneumoconioses (revised 1968), Occupational Safety and Health Series No. 22, pp. 21-24. International Labour Office, Geneva.

Jacobson, G., Bohlig, H., and Kiviluoto, R. (1970). Essentials of chest radiography. Radiology, 95, 445-450.

McLintock, J. S. (1971). The selection of juvenile entrants to mining. British Journal of Industrial Medicine, 28, 45-51.

Rogan, J. M. (1971). National Coal Board Medical Service and Medical Research, Annual Report 1970-71, pp. 8-14. National Coal Board, London.

Received for publication December 6, 1972

Accepted for publication May 11, 1973

\section{Appendix}

Preferences by Reader, Survey, and Chest Diameter (Criterion 1)

\begin{tabular}{|c|c|c|c|c|c|}
\hline Reader & Survey & \multicolumn{4}{|c|}{ Number of preferences } \\
\hline \multicolumn{2}{|c|}{ Chest diameter (in $\mathrm{mm}$ ) } & $\begin{array}{c}<254 \\
a\end{array}$ & $\underset{b}{\geqslant 254}$ & $\begin{array}{c}<254 \\
c\end{array}$ & $\underset{d}{\geqslant 254}$ \\
\hline 1 & $\begin{array}{l}\text { A } \\
\text { B } \\
\text { C }\end{array}$ & $\begin{array}{r}6 \\
10 \\
17\end{array}$ & $\begin{array}{r}41 \\
7 \\
7\end{array}$ & $\begin{array}{r}5 \\
46 \\
24\end{array}$ & $\begin{array}{l}38 \\
42 \\
18\end{array}$ \\
\hline 2 & $\begin{array}{l}\text { A } \\
\text { B } \\
\text { C }\end{array}$ & $\begin{array}{l}10 \\
20 \\
17\end{array}$ & $\begin{array}{l}58 \\
22 \\
18\end{array}$ & $\begin{array}{r}5 \\
31 \\
42\end{array}$ & $\begin{array}{l}33 \\
15 \\
13\end{array}$ \\
\hline 3 & $\begin{array}{l}\mathbf{A} \\
\mathbf{B} \\
\mathbf{C}\end{array}$ & $\begin{array}{r}7 \\
12 \\
4\end{array}$ & $\begin{array}{r}72 \\
22 \\
8\end{array}$ & $\begin{array}{r}2 \\
38 \\
22\end{array}$ & $\begin{array}{l}28 \\
22 \\
13\end{array}$ \\
\hline 4 & $\begin{array}{l}\mathbf{A} \\
\mathbf{B} \\
\mathbf{C}\end{array}$ & $\begin{array}{l}41 \\
21 \\
17\end{array}$ & $\begin{array}{r}111 \\
13 \\
14\end{array}$ & $\begin{array}{l}15 \\
34 \\
77\end{array}$ & $\begin{array}{l}49 \\
10 \\
25\end{array}$ \\
\hline 5 & $\begin{array}{l}\text { A } \\
\text { B } \\
\mathbf{C}\end{array}$ & $\begin{array}{l}14 \\
22 \\
41\end{array}$ & $\begin{array}{l}81 \\
19 \\
27\end{array}$ & $\begin{array}{l}13 \\
36 \\
49\end{array}$ & $\begin{array}{r}48 \\
11 \\
9\end{array}$ \\
\hline
\end{tabular}


An estimate of the effect of chest thickness on each reader's preference can be obtained by pooling results from the three surveys.

Under the null hypotheses that differences in a particular reader's preferences for films between surveys are due only to differences in the proportions of film pairs from men with chest diameters less than $254 \mathrm{~mm}$

$$
\begin{aligned}
& \mathrm{E}\left(\mathrm{a}_{1}\right)=\left(\mathrm{a}_{1}+\mathrm{c}_{1}\right) \Sigma \mathrm{a}_{1} !\left(\Sigma \mathrm{a}_{1}+\Sigma \mathrm{c}_{1}\right) ; \\
& \mathrm{E}\left(\mathrm{b}_{\mathrm{i}}\right)=\left(\mathrm{b}_{\mathrm{i}}+\mathrm{d}_{\mathrm{i}}\right) \Sigma \mathrm{b}_{\mathrm{i}} /\left(\Sigma \mathrm{b}_{\mathrm{i}}+\Sigma \mathrm{d}_{\mathrm{i}}\right) \text {; } \\
& \mathrm{E}\left(\mathrm{c}_{\mathrm{i}}\right)=\left(\mathrm{a}_{\mathrm{i}}+\mathrm{c}_{\mathrm{i}}\right) \Sigma \mathrm{c}_{\mathrm{i}} /\left(\Sigma \mathrm{a}_{\mathrm{i}}+\Sigma \mathrm{c}_{\mathrm{i}}\right) ; \\
& \mathrm{E}\left(\mathrm{d}_{\mathrm{i}}\right)=\left(\mathrm{b}_{\mathrm{i}}+\mathrm{d}_{\mathrm{i}}\right) \Sigma \mathrm{d}_{\mathrm{i}} /\left(\Sigma \mathrm{b}_{\mathrm{i}}+\Sigma \mathrm{d}_{\mathrm{i}}\right) ;
\end{aligned}
$$

where the summations are over the three surveys, $\mathrm{i}=\mathrm{A}, \mathrm{B}, \mathrm{C}$. For each reader, the statistic

$$
\begin{array}{cc}
\sum_{\mathrm{i}} & \sum\left[\mathrm{r}_{\mathrm{i}}-\mathrm{E}(\mathrm{r})\right]^{2} \\
\mathrm{E}(\mathrm{r})
\end{array}
$$

is distributed approximately as $x^{2}$ with three degrees of freedom, where the summations are over the dummy variable $r=a, b, c, d$, and over the three surveys $i=A, B, C$.

Values of $\chi^{2}$ in Table 5 have been corrected for continuity. 